$\begin{array}{ll}\text { Research Square } & \begin{array}{l}\text { Preprints are preliminary reports that have not undergone peer review. } \\ \text { They should not be considered conclusive, used to inform clinical practice, } \\ \text { or referenced by the media as validated information. }\end{array}\end{array}$

\title{
Global trends in clinical trials involving pluripotent stem cells: A systematic multi-database analysis
}

Julia Deinsberger

Medizinische Universitat Wien https://orcid.org/0000-0002-4237-1526

David Reisinger

Medizinische Universität Wien

Benedikt Weber ( $\sim$ benedikt.weber@meduniwien.ac.at)

Medizinische Universitat Wien

\section{Research}

Keywords: iPSCs, ESCs, stem cell research, clinical trials, global distribution, interventional, observational

Posted Date: July 27 th, 2020

DOI: https://doi.org/10.21203/rs.3.rs-47529/v1

License: () (1) This work is licensed under a Creative Commons Attribution 4.0 International License. Read Full License 


\section{Abstract}

Background: Pluripotent stem cells (PSCs) hold great potential for novel therapeutic approaches to regenerate or replace functionally impaired tissues. Since the introduction of the induced pluripotent stem cell technology in 2006, the number of scientific publications on this topic has constantly been increasing. However, so far no therapy based on PSCs has found its way into routine clinical use.

Methods: In this study, we examined research trends related to clinical trials involving PSCs based on data obtained from ClinicalTrial.gov, the ICTRP database from the World Health Organization, as well as from a search of all individual databases that are included in the ICTRP using a multistep search algorithm.

Results: 131 studies could be classified as clinical trials involving PSCs and were included into further analyses. The magnitude of these studies (77.1\%) was observational, which implies that no cells were transplanted into patients, and only a minority of studies (22.9\%) had an interventional character. The number of clinical trials involving induced pluripotent stem cells (iPSCs, $74.8 \%$ ) was substantially higher than the one involving embryonic stem cells (ESCs, $25.2 \%$ ). However, the picture changes when focusing on interventional studies, where in the majority (73.3\%) of cases ESCs were used. Interestingly, the study duration was significantly shorter for interventional versus observational trials $(\mathrm{p}=0.002)$. When focusing on the geographical study regions, it became obvious that the greatest part of all observational trials was performed in the USA (41.6\%) and in France (16.8\%), while the magnitude of interventional studies was performed in Asian countries (China 36.7\%, Japan 13.3\%, South Korea 10.0\%) and in the field of ophthalmology.

Conclusions: These results indicate that only a limited number of trials were focusing on the actual transplantation of PSCs into patients in a rather narrow field of diagnoses. The majority of interventional trials involving PSCs took place in Asian countries and in the field of ophthalmology. The future will tell us, if the iPSC technology will ultimately overcome the current challenges and will finally make its way into routine clinical use.

\section{Introduction}

Pluripotent stem cells are defined by their self-renewal capacity and ability to differentiate into any cellular phenotype of the human body (1). This plasticity has generated significant hope for therapies that may enable repair of functionally impaired tissues $(2,3)$. Several studies involving embryonic stem cells (ESCs) have been performed showing initial clinical success (4-6). However, the use of ESCs is limited by several hurdles. Most importantly, the derivation of ESCs is associated with the destruction of human embryos at the blastocyst-stage, which is associated with ethical concerns (7). Secondly, ESCs are isolated from pre-implantation blastocysts and are thus, by their nature, never of autologous origin, which may cause immunological rejection by the host. The generation of induced pluripotent stem cells (iPSCs) alleviated these two major obstacles and thus holds the potential to open up completely new therapeutic options. The essence of iPSCs is that a mature, finally differentiated cell is reprogrammed via insertion of a set of genes, generating a pluripotent cell line for a specific patient (8). Since the first report on iPSCs by Yamanaka et al. in 2006 (9), we have experienced publication of a plethora of studies involving preclinical in vitro $(10,11)$ and in vivo $(12-16)$ as well as first clinical studies in humans $(5,17,18)$ investigating the feasibility and safety of ESCs and iPSCs for therapeutic applications. Ongoing efforts to realize stem cell based therapies for ophthalmic diseases and neurological disorders have so far shown promising results $(5,12,18-20)$. This rapid translation of the technology also supports the enormous potential and application range of pluripotent stem cell research $(8,21,22)$. However, the published information on trials is generally limited by a significant publication bias, implying that negative results may not be published at all. In addition, results may not be published due to a lack of interest by sponsoring institutions or they will be published in different languages. This is of particular interest as growing body evidence has revealed genetic instability, epigenetic abnormalities and immunogenicity of iPSCs, raising safety concerns regarding clinical applications (23-29). Additionally, pluripotent stem cells pose a considerable cancer risk in the recipient, firstly through potential teratoma formation and secondly due to genetic alterations as a consequence to the usage of integrating vectors, creating a risk for reactivation of commonly used reprogramming factors (OCT4, SOX2, MYC and KLF4), which are also highly expressed in various cancer types (26, 30).

This analysis of the 'status quo' of clinical trials on pluripotent stem cellsoffers a comprehensive overview on the actual number and content of clinical trials involving this promising technology. Several studies focusing on the trends in stem cell research have been conducted so far (31-34), However, these studies were either limited regarding the type of stem cell used, such as multipotent stem cells only (34), or their search was conducted using only one database (mostly "ClinicalTrials.gov") (31-34). Even though "ClinicalTrials.gov"(35) is the largest database for clinical trials and represented in over 200 countries around the globe, a search query in this database does not guarantee completeness. Therefore, we complemented our systematic search using the international clinical trials registry platform (ICTRP) (36) from the Word Health Organization (WHO) and further individual databases contained in the ICTRP in order to achieve the most complete overview on clinical trials involving pluripotent stem cells. As part of this systematic analysis a particular focus was also put on the global distribution of the trials, the study type - observational versus interventional -, as well as on the number of patients enrolled.

\section{Methods}

\section{Systematic search of databases}

The aim of the study was to perform a comprehensive analysis of all clinical trials involving pluripotent stem cells based on a defined sequence of database searches. First a search was performed in the database "ClinicalTrials.gov" using the search terms "pluripotent" OR "pluripotent stem cell" OR "induced pluripotent stem cell” OR “iPSC" OR "embryonic stem cell”. In parallel a search was performed on the "International Clinical Trials Registry Platform" (ICTRP) using the identical search terms as mentioned above. This primary search was performed in August 2019. The search algorithm is summarized in Supplementary Fig. 3. In total 177 studies were identified at "ClinicalTrials.gov". Among them, 68 clinical studies had to be excluded, 65 due to a lack of involvement of pluripotent stem cells or because their employment was optional. The 3 remaining studies were excluded since they were withdrawn before enrolling its first participant. This search was complimented by a search on the ICTRP portal site, which is provided by the WHO. This database combines several different national and international databases. These individual databases were searched separately in order to maximize the number of relevant trials 
identified. Based on the ICTRP portal site, 21 additional clinical trials could be added to the final analysis after excluding duplicated search results also obtained from "ClinicalTrials.gov". The individual search of databases included in the ICTRP-based meta search did only detect one additional relevant clinical trial in the "Australian New Zealand Clinical Trials Registry" (ANZCTR). In total, 131 appropriate clinical trials involving pluripotent stem cells were identified, downloaded and consistently analyzed using Microsoft Excel (Microsoft Inc., USA). The following properties of the 131 studies have been content of the analysis: "Registration number" (NCT number, if possible), "study title", "recruitment status", "study type" (observational or interventional), "type of stem cell" (hESC or hiPSC), "study target", "target disease", "corresponding organ system", "sponsor", "location", "study start", "estimated study completion" and "number enrolled".

\section{Content Analysis Of Clinical Trials}

The studies were generally classified as observational or interventional study types by the study authors. However, in some cases the "interventional" type of the study mentioned on the database was derived from an "invasive" cell harvesting procedure only, such as a blood draw or a skin biopsy. In our analysis the term "interventional" study type was uniformly reserved for studies, in which cells were (re)transplanted into a patient using an interventional procedure by itself. An invasive cell harvesting procedure, such as a blood draw, was not sufficient to fulfill this criterion. Accordingly, a clinical trial was assigned to the "observational" study type, if the intervention only served to obtain primary cells. Based on these considerations, 20 apparently "interventional" clinical trials were re-categorized as "observational" studies. In 2 supposedly "observational" clinical trials it was the other way round, they were re-categorized as "interventional" clinical trials. The search for clinical trials and parts of the results section were generated as part of a medical diploma thesis of the first author of this publication.

\section{Biostatistical Analysis}

All data are presented in percentage (and absolute numbers). The study duration of different study types was compared using an unpaired Student-T-test. $\mathrm{P}$ values $<0.05$ were considered statistically significant. All analyses were performed using either Microsoft Excel (Microsoft Inc., USA) or SPSS 24.0 (SPSS Inc., USA). Individual sub-groups were compared graphically in the form of pie or bar charts. In addition, choropleth maps, generated using Microsoft Excel (Microsoft Inc., USA), were used to indicate the geographical distribution of the involved studies.

\section{Results}

\section{Results of the systematic multi-database search algorithm}

In the database search using "ClinicalTrials.gov" 177 studies were identified when using the predefined search criteria. Out of those, 65 studies had to be excluded, because they did not involve pluripotent stem cells at all or their employment was optional. 3 studies were excluded, because they had to be withdrawn before enrolling the first participant. Hence, 109 studies remained for further in-depth analysis. Searching the meta-database ICTRP using the same predefined search criteria added 21 additional clinical trials, which were not found in the search using "ClinicalTrials.gov". The individual search of all databases that are included in the ICTRP did detect one additional relevant clinical trial in the "Australian New Zealand Clinical Trials Registry" (ANZCTR). Altogether, 131 clinical trials involving human pluripotent stem cells were identified and included into further in-depth analyses. For a detailed list of all trials please refer to Supplementary Table 01.

\section{Global distribution of clinical trials involving pluripotent stem cells}

All clinical trials were classified according to the country or area they were conducted in. Overall, $36 \%$ (47) of all trials were conducted in the USA, $15 \%$ (19) in France, 12\% (16) in China, 9\% (12) in Japan, 6\% (8) in the United Kingdom (UK), 6\% (8) in Israel, 4\% (5) in Germany, 2\% (3) in South Korea, 2\% (3) in Australia, 2\% (3) in Pakistan, 2\% (2) in Taiwan, 1\% (1) in Brazil, 1\% (1) in India, 1\% (1) in Italy, 1\% (1) in the Netherlands and 1\% (1) in Iran (see Fig. 1a-b). The study could be classified as interventional trial in $22.9 \%$ (30) and as observational in $77.1 \%$ (101). When focusing on interventional studies (characterized by a

(re-)transplantation of PSCs into humans), China was by far the leading country with $36.7 \%$ (11) of all interventional studies. Also in the USA (16.7\%, 5 ), Japan $(13.4 \%, 4)$ and South Korea $(10.0 \%, 3)$ several interventional studies have been performed (Fig. 1c and f). The distribution of observational clinical studies across the globe was as follows: $41.6 \%$ (42) of the trials took place in the USA, 16.8\% (17) in France, 7.9\% (8) in Japan, 5.9\% (6) in the UK, 6.9\% (7) in Israel, $5.0 \%$ (5) in Germany and 5.0\% (5) in China (see Fig. 1d and g). These results indicate that, although most studies are performed in the USA, a magnitude of these studies have an observational character. In China much less studies are performed in total, however, with the majority of them being interventional. This trend can also be observed for other Asian countries, such as Japan or South Korea. In total, all studies together comprise 15,540 participants. Interventional studies involved $15.0( \pm 15.0)$ participants on average, compared to an average of $149.4( \pm 389.1)$ participants in observational studies. It therefore becomes obvious, that most study participants can be found in countries, in which a particularly large number of observational clinical studies were performed. $50.2 \%$ (7798) of all participants were included into studies in the USA, followed by $20.2 \%$ (3139) in the UK and 10.2\% (1585) in France (see Fig. 1e). China, South Korea and Brazil are the only countries in which both, the amount of study participants and the number of studies, is higher for interventional clinical trials than for observational ones. In European countries the numbers of studies and patients of observational trials clearly exceeds the ones of interventional studies. There are even several European countries, where no interventional study involving PSCs was found at all (e.g. Germany, Italy and the Netherlands; see. Figure 1h). In addition, it could be observed, that in many countries not a single clinical trial involving PSCs is registered. This applies e.g. to all countries on the African continent, Russia, large parts of Europe and Southern America.

\section{Target diseases of clinical trials involving pluripotent stem cells}


PSCs have been investigated regarding the treatment of various diseases affecting several different organ systems. We therefore analyzed all clinical trials obtained using the multistep search algorithm regarding the targeted disease. The diseases were classified according to the Global Burden of Disease Study 2017 (37) (Fig. 2a). Sense organ diseases, more precisely ophthalmic diseases, were targeted in the highest number of clinical trials (24.4\%, 32) followed by other non-communicable diseases $(22.1 \%, 29)$, cardiovascular diseases $(14.5 \%, 19)$ and neurological disorders $(13.0 \%, 17)$. For a detailed overview please refer to Fig. $2 b$.

The category "other non-communicable diseases" includes studies focusing on metabolic diseases (6.9\% of all studies, 9), genetic syndromes (6.1\%, 8), reproductive and urogenital diseases $(3.8 \%, 5)$, defects of the immune system $(2.3 \%, 3)$, hematologic disorders $(2.3 \%, 3)$ and otorhinolaryngologic diseases $(0.8 \%, 1)$ (Fig. 2a). The category "none" includes studies that are concerned with the assessment of reprogramming processes $(2.3 \%$ of all studies, 3$)$ the exploration of differentiation mechanisms $(2.3 \%, 3)$ and cell banking $(1.5 \%, 2)$. Analysis of the different disease categories involved in observational type clinical trials revealed that mainly the following diseases were targeted: Other non-communicable diseases $(25.7 \%, 26)$, cardiovascular diseases (16.8\%, 17$)$, neurological disorders $(12.9 \%, 13)$ and organ sense diseases $(12.9 \%, 13)$ (Fig. 2c). Interventional clinical trials focused on sense organ diseases $(63.3 \%, 19)$, holding a big lead over neurological disorders $(13.3 \%, 4)$, other non-communicable diseases $(10 \%, 3)$, cardiovascular diseases $(6.7 \%, 2)$, neoplasms $(3.3 \%, 1)$ and musculoskeletal disorders $(3.3 \%, 1)$ (Fig. 2d). In summary, ophthalmic diseases are in the main focus of a major part of all clinical trials involving human PSCs, especially regarding interventional studies. If the categories including ophthalmic diseases and neurological disorders are combined, this group represents the majority of interventional PSC clinical trials $(76.6 \%, 23)$. Trials focusing on ophthalmic diseases, neurological disorders and cardiovascular diseases account for $51.9 \%$ (68) of all PSC - studies.

\section{Study duration of clinical trials}

The study duration of clinical trials involving PSCs was analyzed according to the information available from the different databases. The mean duration of trials involving hESCs was $5.8(+/-5.1)$ years compared to $5.2(+/-4.2)$ years for studies using hiPSCs $(p=0.635 ;$ see Fig. 3 and Suppl. Figure 1$)$. Clinical trials of the interventional type were significantly shorter (3.8 years, $+/-1.8$ ) compared to studies of the observational type (5.9 years $(+/-5.0), p=0.002$, see Fig. 4 and Suppl. Figure 2). However, only 106 out of 131 trials could be considered, since the end date was not mentioned in 25 (19.1\%) trials.

\section{Type of study and type of stem cells used}

$77.1 \%$ (101) of all clinical trials involving human PSCs were observational, while $22.9 \%$ (30) were interventional. In 73.3\% (22) of interventional studies hESCs were used, while iPSCs were involved in only $26.7 \%$ (8). The origin of the cells was allogeneic in $93.3 \%$ (28) and autologous in $0.7 \%(2)$. However, when it comes to observational clinical trials, the frequency of the used stem cell type is vice versa. In these studies, hESCs were used in only $10.9 \%$ (11), while iPSCs were employed in $89.1 \%(90)$. The distribution of all clinical trials dependent on the characteristics interventional/observational and hESC/iPSC is summarized in Fig. 5a. In-depth analysis of the geographical distribution of clinical trials using different types of hPSCs revealed that most studies involving hESCs were conducted in China $(33.3 \%$; 11$)$, followed by the USA $(27.3 \%, 9)$, Israel $(12.2 \%$, 4), the UK $(9.1 \%, 3)$ and South Korea $(9.1 \%, 3)$ (see Fig. 5b). Concerning clinical trials involving hiPSC, 38.4\% (38) were performed in the USA, 17.2\% (17) in France and $12.1 \%$ (12) in Japan (see Fig. 5c)

\section{Study design and clinical study phase of interventional trials}

All interventional studies were open label, non-randomized (100.0\%, 30). 90.0\% (27) were carried out in one center and 10.0\% (3) were multi-center studies. The studies comprised one single arm in $43.3 \%$ (14), in $40 \%$ (13) the trials enclosed two or more intervention groups, each receiving treatment with pluripotent stem cells (or cells derived from pluripotent stem cells), $6.7 \%$ (2) of the studies included a group without intervention and $3.3 \%$ (1) a historical control.

In $30 \%$ (9) the trial was categorized as Phase I study by the authors, in $50.0 \%$ (15) as Phase I/II, in $6.7 \%$ (2) the authors declared that this categorization is not applicable and in $13.3 \%$ (4) no information regarding the clinical study phase was given. For details on interventional studies please refer to Table 01 and Supplementary Table 02. 
Table 01

Characteristics of interventional clinical trials involving pluripotent stem cells.

\begin{tabular}{|c|c|c|c|c|c|c|c|c|c|}
\hline ID number & Title & Cell type & Origin & Target disease & $\begin{array}{l}\text { Country or } \\
\text { area }\end{array}$ & $\begin{array}{l}\text { Study } \\
\text { design }\end{array}$ & $\begin{array}{l}\text { No. } \\
\text { patients } \\
\text { enrolled }\end{array}$ & Study groups & Intel \\
\hline NCT03222453 & $\begin{array}{l}\text { Thalassemia } \\
\text { Treatment } \\
\text { Based on the } \\
\text { Stem Cell } \\
\text { Technology }\end{array}$ & hiPSC & autologous & $\begin{array}{l}\text { Beta- } \\
\text { Thalassemia }\end{array}$ & China & $\begin{array}{l}\text { Open } \\
\text { Label }\end{array}$ & 2 & $\begin{array}{l}\text { Intervention/ } \\
\text { No Intervention }\end{array}$ & $\begin{array}{l}\text { Injec } \\
\text { hem } \\
\text { sten }\end{array}$ \\
\hline NCT01674829 & $\begin{array}{l}\text { A Phase I/Ila, } \\
\text { Open-Label, } \\
\text { Single-Center, } \\
\text { Prospective } \\
\text { Study to } \\
\text { Determine the } \\
\text { Safety and } \\
\text { Tolerability of } \\
\text { Sub-retinal } \\
\text { Transplantation } \\
\text { of Human } \\
\text { Embryonic Stem } \\
\text { Cell Derived } \\
\text { Retinal } \\
\text { Pigmented } \\
\text { Epithelial(MA09- } \\
\text { hRPE) Cells in } \\
\text { Patients With } \\
\text { Advanced Dry } \\
\text { Age-related } \\
\text { Macular } \\
\text { Degeneration }\end{array}$ & $\begin{array}{l}\text { hESC-derived } \\
\text { RPE; MA09- } \\
\text { hRPE }\end{array}$ & allogeneic & $\begin{array}{l}\text { Dry Age Related } \\
\text { Macular } \\
\text { Degeneration }\end{array}$ & South Korea & $\begin{array}{l}\text { Open } \\
\text { Label }\end{array}$ & 12 & $\begin{array}{l}4 \text { groups, } \\
\text { different } \\
\text { number of cells }\end{array}$ & $\begin{array}{l}\text { Sub } \\
\text { Tran }\end{array}$ \\
\hline NCT02903576 & $\begin{array}{l}\text { Stem Cell } \\
\text { Therapy for } \\
\text { Outer Retinal } \\
\text { Degenerations }\end{array}$ & $\begin{array}{l}\text { hESC-derived } \\
\text { RPE }\end{array}$ & allogeneic & $\begin{array}{l}\text { Age Related } \\
\text { Macular } \\
\text { Degeneration, } \\
\text { Stargardt's } \\
\text { Disease or } \\
\text { Exudative Age- } \\
\text { related Macular } \\
\text { Degeneration }\end{array}$ & Brazil & $\begin{array}{l}\text { Open } \\
\text { Label }\end{array}$ & 18 & $\begin{array}{l}2 \text { active } \\
\text { comparators }\end{array}$ & $\begin{array}{l}\text { Injec } \\
\text { hES } \\
\text { suss } \\
\text { vers } \\
\text { of h } \\
\text { seec } \\
\text { subs }\end{array}$ \\
\hline NCT01625559 & $\begin{array}{l}\text { Safety and } \\
\text { Tolerability of } \\
\text { MA09-hRPE } \\
\text { Cells in Patients } \\
\text { With Stargardt's } \\
\text { Macular } \\
\text { Dystrophy(SMD) }\end{array}$ & $\begin{array}{l}\text { hESC-derived } \\
\text { RPE cells } \\
\text { (MA09-hRPE) }\end{array}$ & allogeneic & $\begin{array}{l}\text { Stargardt's } \\
\text { Macular } \\
\text { Dystrophy }\end{array}$ & South Korea & $\begin{array}{l}\text { Open } \\
\text { Label }\end{array}$ & 3 & Single arm & $\begin{array}{l}\text { Sub. } \\
\text { tran: }\end{array}$ \\
\hline NCT03763136 & $\begin{array}{l}\text { Treating Heart } \\
\text { Failure With } \\
\text { hPSC-CMs }\end{array}$ & $\begin{array}{l}\text { hiPSCs- derived } \\
\text { cardiomyocytes }\end{array}$ & allogeneic & Heart Failure & China & $\begin{array}{l}\text { Open } \\
\text { Label }\end{array}$ & 5 & Single arm & $\begin{array}{l}\text { Injec } \\
\text { the } \\
\text { myo }\end{array}$ \\
\hline NCT03046407 & $\begin{array}{l}\text { Treatment of } \\
\text { Dry Age Related } \\
\text { Macular } \\
\text { Degeneration } \\
\text { Disease With } \\
\text { Retinal Pigment } \\
\text { Epithelium } \\
\text { Derived From } \\
\text { Human } \\
\text { Embryonic Stem } \\
\text { Cells }\end{array}$ & $\begin{array}{l}\text { hESC-derived } \\
\text { RPE }\end{array}$ & allogeneic & $\begin{array}{l}\text { Dry Age-related } \\
\text { Macular } \\
\text { Degeneration }\end{array}$ & China & $\begin{array}{l}\text { Open } \\
\text { Label }\end{array}$ & 10 & Single arm & $\begin{array}{l}\text { Sub } \\
\text { tran: }\end{array}$ \\
\hline NCT03944239 & $\begin{array}{l}\text { Safety and } \\
\text { Efficacy of } \\
\text { Subretinal } \\
\text { Transplantation } \\
\text { of Clinical } \\
\text { Human } \\
\text { Embryonic Stem } \\
\text { Cell Derived } \\
\text { Retinal Pigment } \\
\text { Epitheliums in } \\
\text { Treatment of } \\
\text { Retinitis } \\
\text { Pigmentosa }\end{array}$ & $\begin{array}{l}\text { hESC-derived } \\
\text { RPE }\end{array}$ & allogeneic & $\begin{array}{l}\text { Retinitis } \\
\text { pigmentosa }\end{array}$ & China & $\begin{array}{l}\text { Open } \\
\text { Label }\end{array}$ & 10 & Single arm & $\begin{array}{l}\text { Sub } \\
\text { tran: }\end{array}$ \\
\hline
\end{tabular}




\begin{tabular}{|c|c|c|c|c|c|c|c|c|c|}
\hline ID number & Title & Cell type & Origin & Target disease & $\begin{array}{l}\text { Country or } \\
\text { area }\end{array}$ & $\begin{array}{l}\text { Study } \\
\text { design }\end{array}$ & $\begin{array}{l}\text { No. } \\
\text { patients } \\
\text { enrolled }\end{array}$ & Study groups & Intel \\
\hline NCT03482050 & $\begin{array}{l}\text { Study to } \\
\text { Evaluate } \\
\text { Transplantation } \\
\text { of Astrocytes } \\
\text { Derived From } \\
\text { Human } \\
\text { Embryonic Stem } \\
\text { Cells, in Patients } \\
\text { With } \\
\text { Amyotrophic } \\
\text { Lateral Sclerosis }\end{array}$ & $\begin{array}{l}\text { hESC-derived } \\
\text { astrocytes }\end{array}$ & allogeneic & $\begin{array}{l}\text { Amyotrophic } \\
\text { Lateral Sclerosis }\end{array}$ & Israel & $\begin{array}{l}\text { Open } \\
\text { Label }\end{array}$ & 21 & $\begin{array}{l}\text { Dose- } \\
\text { escalation, } 4 \\
\text { groups }\end{array}$ & $\begin{array}{l}\text { intra } \\
\text { (spir } \\
\text { injec }\end{array}$ \\
\hline NCT02755428 & $\begin{array}{l}\text { Subretinal } \\
\text { Transplantation } \\
\text { of Retinal } \\
\text { Pigment } \\
\text { Epitheliums in } \\
\text { Treatment of } \\
\text { Age-related } \\
\text { Macular } \\
\text { Degeneration } \\
\text { Diseases }\end{array}$ & $\begin{array}{l}\text { hESC-derived } \\
\text { RPE }\end{array}$ & allogeneic & $\begin{array}{l}\text { Dry Age-related } \\
\text { Macular } \\
\text { Degeneration }\end{array}$ & China & $\begin{array}{l}\text { Open } \\
\text { Label }\end{array}$ & 10 & Single arm & $\begin{array}{l}\text { Sub } \\
\text { tran: }\end{array}$ \\
\hline NCT03119636 & $\begin{array}{l}\text { Safety and } \\
\text { Efficacy Study } \\
\text { of Human ESC- } \\
\text { derived Neural } \\
\text { Precursor Cells } \\
\text { in the Treatment } \\
\text { of Parkinson's } \\
\text { Disease }\end{array}$ & $\begin{array}{l}\text { hESC- derived } \\
\text { neural } \\
\text { precursor cells }\end{array}$ & allogeneic & $\begin{array}{l}\text { Parkinson's } \\
\text { disease }\end{array}$ & China & $\begin{array}{l}\text { Open } \\
\text { Label }\end{array}$ & 50 & $\begin{array}{l}3 \text { groups: } \\
\text { Levodopa 1) + } \\
\text { NPC 2) + HLA- } \\
\text { matched NPC, } \\
\text { 3) + HLA-non- } \\
\text { matched NPC }\end{array}$ & $\begin{array}{l}\text { Ster } \\
\text { intra } \\
\text { injec }\end{array}$ \\
\hline NCT02286089 & $\begin{array}{l}\text { Safety and } \\
\text { Efficacy Study } \\
\text { of OpRegen for } \\
\text { Treatment of } \\
\text { Advanced Dry- } \\
\text { Form Age- } \\
\text { Related Macular } \\
\text { Degeneration }\end{array}$ & $\begin{array}{l}\text { hESC-derived } \\
\text { RPE }\end{array}$ & allogeneic & $\begin{array}{l}\text { Age-related } \\
\text { Macular } \\
\text { Degeneration }\end{array}$ & USA + Israel & $\begin{array}{l}\text { Open } \\
\text { Label }\end{array}$ & 24 & $\begin{array}{l}\text { Dose- } \\
\text { escalation, } 4 \\
\text { groups }\end{array}$ & $\begin{array}{l}\text { Sub } \\
\text { tran: }\end{array}$ \\
\hline NCT03877471 & $\begin{array}{l}\text { Mesenchymal } \\
\text { Stem Cells - Like } \\
\text { Cell } \\
\text { Transplantation } \\
\text { in Women With } \\
\text { Primary Ovarian } \\
\text { Insufficiency }\end{array}$ & $\begin{array}{l}\text { hESC-derived } \\
\text { MSC-like cells }\end{array}$ & allogeneic & $\begin{array}{l}\text { Primary Ovarian } \\
\text { Insufficiency }\end{array}$ & China & $\begin{array}{l}\text { Open } \\
\text { Label }\end{array}$ & 28 & $\begin{array}{l}3 \text { groups: low, } \\
\text { medium and } \\
\text { high dosage of } \\
\text { cells }\end{array}$ & $\begin{array}{l}\text { Injec } \\
\text { ovar } \\
\text { bilat }\end{array}$ \\
\hline NCT03841110 & $\begin{array}{l}\text { FT500 as } \\
\text { Monotherapy } \\
\text { and in } \\
\text { Combination } \\
\text { With Immune } \\
\text { Checkpoint } \\
\text { Inhibitors in } \\
\text { Subjects With } \\
\text { Advanced Solid } \\
\text { Tumors }\end{array}$ & $\begin{array}{l}\text { iPSC-derived } \\
\text { NK cell cancer } \\
\text { immunotherapy }\end{array}$ & allogeneic & $\begin{array}{l}\text { advanced solid } \\
\text { tumors }\end{array}$ & USA & $\begin{array}{l}\text { Open } \\
\text { Label }\end{array}$ & 76 & $\begin{array}{l}\text { 1) FT500 } \\
\text { Monotherapy, } \\
\text { 2) FT500 in } \\
\text { Combination } \\
\text { with Immune } \\
\text { Checkpoint } \\
\text { Inhibitor } \\
\text { nivolumab, } \\
\text { pembrolizumab } \\
\text { or } \\
\text { atezolizumab }\end{array}$ & \\
\hline $\begin{array}{l}\text { JPRN- } \\
\text { UMIN000032989 }\end{array}$ & $\begin{array}{l}\text { Clinical trial of } \\
\text { human } \\
\text { (allogeneic) } \\
\text { induced } \\
\text { pluripotent stem } \\
\text { cell-derived } \\
\text { cardiomyocyte } \\
\text { sheet for severe } \\
\text { cardiomyopathy }\end{array}$ & $\begin{array}{l}\text { iPS cell-derived } \\
\text { cardiomyocytes }\end{array}$ & allogeneic & $\begin{array}{l}\text { Ischemic } \\
\text { cardiomyopathy }\end{array}$ & Japan & $\begin{array}{l}\text { Open } \\
\text { Label }\end{array}$ & 3 & Single arm & $\begin{array}{l}\text { iPS } \\
\text { card } \\
\text { she€ } \\
\text { tran }\end{array}$ \\
\hline NCT03963154 & $\begin{array}{l}\text { Interventional } \\
\text { Study of } \\
\text { Implantation of } \\
\text { hESC-derived } \\
\text { RPE in Patients } \\
\text { With RP Due to } \\
\text { Monogenic } \\
\text { Mutation }\end{array}$ & $\begin{array}{l}\text { hESC-derived } \\
\text { RPE }\end{array}$ & allogeneic & $\begin{array}{l}\text { Retinitis } \\
\text { Pigmentosa Due } \\
\text { to Monogenic } \\
\text { Mutation }\end{array}$ & France & $\begin{array}{l}\text { Open } \\
\text { Label }\end{array}$ & 12 & $\begin{array}{l}2 \text { sequential } \\
\text { cohorts: } 1 \text { ) } \\
\text { very advanced } \\
\text { and } 2 \text { ) less } \\
\text { advanced loss } \\
\text { of visual acuity }\end{array}$ & $\begin{array}{l}\text { sing } \\
\text { subi } \\
\text { impl } \\
\text { a hE } \\
\text { RPE } \\
\text { in or }\end{array}$ \\
\hline
\end{tabular}




\begin{tabular}{|c|c|c|c|c|c|c|c|c|c|}
\hline ID number & Title & Cell type & Origin & Target disease & $\begin{array}{l}\text { Country or } \\
\text { area }\end{array}$ & $\begin{array}{l}\text { Study } \\
\text { design }\end{array}$ & $\begin{array}{l}\text { No. } \\
\text { patients } \\
\text { enrolled }\end{array}$ & Study groups & Intel \\
\hline NCT03305029 & $\begin{array}{l}\text { The Safety and } \\
\text { Tolerability of } \\
\text { Sub-retinal } \\
\text { Transplantation } \\
\text { of SCNT-hES- } \\
\text { RPE Cells in } \\
\text { Patients with } \\
\text { Advanced Dry } \\
\text { AMD }\end{array}$ & $\begin{array}{l}\text { SCNT hESC- } \\
\text { derived RPE }\end{array}$ & allogeneic & $\begin{array}{l}\text { Dry Age-Related } \\
\text { Macular } \\
\text { Degeneration }\end{array}$ & South Korea & $\begin{array}{l}\text { Open- } \\
\text { Label }\end{array}$ & 3 & Single arm & $\begin{array}{l}\text { Sub } \\
\text { tran }\end{array}$ \\
\hline NCT02057900 & $\begin{array}{l}\text { Transplantation } \\
\text { of Human } \\
\text { Embryonic Stem } \\
\text { Cell-derived } \\
\text { Progenitors in } \\
\text { Severe Heart } \\
\text { Failure } \\
\text { (ESCORT) }\end{array}$ & $\begin{array}{l}\text { hESC- derived } \\
\text { CD } 15 \text { + Isl-1 + } \\
\text { progenitors }\end{array}$ & allogeneic & $\begin{array}{l}\text { Ischemic Heart } \\
\text { Disease }\end{array}$ & France & $\begin{array}{l}\text { Open- } \\
\text { Label }\end{array}$ & 10 & Single arm & $\begin{array}{l}\text { fibriı } \\
\text { emb } \\
\text { hES } \\
\text { CD1 } \\
\text { proc }\end{array}$ \\
\hline NCT01469832 & $\begin{array}{l}\text { Safety and } \\
\text { Tolerability of } \\
\text { Sub-retinal } \\
\text { Transplantation } \\
\text { of Human } \\
\text { Embryonic Stem } \\
\text { Cell Derived } \\
\text { Retinal } \\
\text { Pigmented } \\
\text { Epithelial (hESC- } \\
\text { RPE) Cells in } \\
\text { Patients with } \\
\text { Stargardt's } \\
\text { Macular } \\
\text { Dystrophy } \\
\text { (SMD) }\end{array}$ & $\begin{array}{l}\text { hESC-derived } \\
\text { RPE cells } \\
\text { (MA09-hRPE) }\end{array}$ & allogeneic & $\begin{array}{l}\text { Stargardt's } \\
\text { Macular } \\
\text { Dystrophy }\end{array}$ & UK & $\begin{array}{l}\text { Open- } \\
\text { Label, } \\
\text { Multi- } \\
\text { Center }\end{array}$ & 12 & $\begin{array}{l}\text { Dose- } \\
\text { escalation; } 5 \\
\text { cohorts - } 4 \text { low } \\
\text { vision cohorts } \\
\text { and } 1 \text { better } \\
\text { vision cohort }\end{array}$ & $\begin{array}{l}\text { Sub } \\
\text { injec }\end{array}$ \\
\hline NCT01345006 & $\begin{array}{l}\text { Sub-retinal } \\
\text { Transplantation } \\
\text { of hESC Derived } \\
\text { RPE(MA09- } \\
\text { hRPE)Cells in } \\
\text { Patients With } \\
\text { Stargardt's } \\
\text { Macular } \\
\text { Dystrophy }\end{array}$ & $\begin{array}{l}\text { hESC-derived } \\
\text { RPE cells } \\
\text { (MA09-hRPE) }\end{array}$ & allogeneic & $\begin{array}{l}\text { Stargardt's } \\
\text { Macular } \\
\text { Dystrophy }\end{array}$ & USA & $\begin{array}{l}\text { Open- } \\
\text { Label, } \\
\text { Multi- } \\
\text { Center }\end{array}$ & 13 & $\begin{array}{l}\text { Dose- } \\
\text { escalation; } 5 \\
\text { cohorts - } 4 \text { low } \\
\text { vision cohorts } \\
\text { and } 1 \text { better } \\
\text { vision cohort }\end{array}$ & $\begin{array}{l}\text { Sub } \\
\text { injec }\end{array}$ \\
\hline NCT01344993 & $\begin{array}{l}\text { Safety and } \\
\text { Tolerability of } \\
\text { Sub-retinal } \\
\text { Transplantation } \\
\text { of hESC Derived } \\
\text { RPE (MA09- } \\
\text { hRPE) Cells in } \\
\text { Patients With } \\
\text { Advanced Dry } \\
\text { Age Related } \\
\text { Macular } \\
\text { Degeneration }\end{array}$ & $\begin{array}{l}\text { hESC-derived } \\
\text { RPE cells } \\
\text { (MA09-hRPE) }\end{array}$ & allogeneic & $\begin{array}{l}\text { Dry Age-Related } \\
\text { Macular } \\
\text { Degeneration }\end{array}$ & USA & $\begin{array}{l}\text { Open- } \\
\text { Label, } \\
\text { Multi- } \\
\text { Center }\end{array}$ & 13 & $\begin{array}{l}\text { Dose- } \\
\text { escalation; } 5 \\
\text { cohorts - } 4 \text { low } \\
\text { vision cohorts } \\
\text { and } 1 \text { better } \\
\text { vision cohort }\end{array}$ & $\begin{array}{l}\text { Sub } \\
\text { injec }\end{array}$ \\
\hline $\begin{array}{l}\text { JPRN- } \\
\text { UMIN000011929 }\end{array}$ & $\begin{array}{l}\text { A Study of } \\
\text { transplantation } \\
\text { of autologous } \\
\text { induced } \\
\text { pluripotent stem } \\
\text { cell (iPSC) } \\
\text { derived retinal } \\
\text { pigment } \\
\text { epithelium (RPE) } \\
\text { cell sheet in } \\
\text { subjects with } \\
\text { exudative age } \\
\text { related macular } \\
\text { degeneration }\end{array}$ & $\begin{array}{l}\text { hiPSC-derived } \\
\text { RPE }\end{array}$ & autologous & $\begin{array}{l}\text { Exudative age- } \\
\text { related macular } \\
\text { degeneration }\end{array}$ & Japan & $\begin{array}{l}\text { Open } \\
\text { Label }\end{array}$ & 6 & Single arm & $\begin{array}{l}\text { Tran } \\
\text { of if } \\
\text { RPE }\end{array}$ \\
\hline
\end{tabular}




\begin{tabular}{|c|c|c|c|c|c|c|c|c|c|}
\hline ID number & Title & Cell type & Origin & Target disease & $\begin{array}{l}\text { Country or } \\
\text { area }\end{array}$ & $\begin{array}{l}\text { Study } \\
\text { design }\end{array}$ & $\begin{array}{l}\text { No. } \\
\text { patients } \\
\text { enrolled }\end{array}$ & Study groups & Intel \\
\hline NCT02590692 & $\begin{array}{l}\text { Study of } \\
\text { Subretinal } \\
\text { Implantation of } \\
\text { Human } \\
\text { Embryonic Stem } \\
\text { Cell-Derived RPE } \\
\text { Cells in } \\
\text { Advanced Dry } \\
\text { AMD }\end{array}$ & $\begin{array}{l}\text { hESC-derived } \\
\text { RPE }\end{array}$ & allogeneic & $\begin{array}{l}\text { Dry Age-Related } \\
\text { Macular } \\
\text { Degeneration }\end{array}$ & USA & $\begin{array}{l}\text { Open } \\
\text { Label }\end{array}$ & 16 & $\begin{array}{l}\text { Treated eye } \\
\text { and non-treated } \\
\text { eye }\end{array}$ & $\begin{array}{l}\text { Sub } \\
\text { impl }\end{array}$ \\
\hline NCT03839238 & $\begin{array}{l}\text { Safety } \\
\text { Observation on } \\
\text { hESC Derived } \\
\text { MSC Like Cell } \\
\text { for the Meniscus } \\
\text { Injury }\end{array}$ & $\begin{array}{l}\text { hESC- derived } \\
\text { MSC like cell }\end{array}$ & allogeneic & Meniscus injury & China & $\begin{array}{l}\text { Open } \\
\text { Label }\end{array}$ & 18 & $\begin{array}{l}\text { Three cohorts } \\
\text { with different } \\
\text { dosages }\end{array}$ & $\begin{array}{l}\text { hES } \\
\text { MSC }\end{array}$ \\
\hline NCT02923375 & $\begin{array}{l}\text { A Study of CYP- } \\
001 \text { for the } \\
\text { Treatment of } \\
\text { Steroid- } \\
\text { Resistant Acute } \\
\text { Graft Versus } \\
\text { Host Disease }\end{array}$ & $\begin{array}{l}\text { iPSC- derived } \\
\text { MSCs }\end{array}$ & allogeneic & $\begin{array}{l}\text { Graft vs Host } \\
\text { Disease }\end{array}$ & $\begin{array}{l}\text { Australia + } \\
\text { UK }\end{array}$ & $\begin{array}{l}\text { Open } \\
\text { Label }\end{array}$ & 16 & $\begin{array}{l}\text { Dose } \\
\text { escalation, } 2 \\
\text { groups }\end{array}$ & $\begin{array}{l}\text { IV in } \\
\text { two }\end{array}$ \\
\hline NCT01691261 & $\begin{array}{l}\text { A Study Of } \\
\text { Implantation Of } \\
\text { Retinal Pigment } \\
\text { Epithelium In } \\
\text { Subjects With } \\
\text { Acute Wet Age } \\
\text { Related Macular } \\
\text { Degeneration }\end{array}$ & $\begin{array}{l}\text { hESC-derived } \\
\text { RPE }\end{array}$ & allogeneic & $\begin{array}{l}\text { Age-Related } \\
\text { Macular } \\
\text { Degeneration }\end{array}$ & UK & $\begin{array}{l}\text { Open } \\
\text { Label }\end{array}$ & 2 & Single arm & $\begin{array}{l}\text { Impl } \\
\text { RPE } \\
\text { imm } \\
\text { a po } \\
\text { men }\end{array}$ \\
\hline NCT02749734 & $\begin{array}{l}\text { Clinical Study of } \\
\text { Subretinal } \\
\text { Transplantation } \\
\text { of Human } \\
\text { Embryo Stem } \\
\text { Cell Derived } \\
\text { Retinal Pigment } \\
\text { Epitheliums in } \\
\text { Treatment of } \\
\text { Macular } \\
\text { Degeneration } \\
\text { Diseases }\end{array}$ & $\begin{array}{l}\text { hESC-derived } \\
\text { RPE }\end{array}$ & allogeneic & $\begin{array}{l}\text { Macular } \\
\text { Degeneration } \\
\text { Stargardt's } \\
\text { Macular } \\
\text { Dystrophy }\end{array}$ & China & $\begin{array}{l}\text { Open } \\
\text { label }\end{array}$ & 15 & Single arm & $\begin{array}{l}\text { Sub } \\
\text { tran: }\end{array}$ \\
\hline $\begin{array}{l}\text { JPRN- } \\
\text { UMIN000033564 }\end{array}$ & $\begin{array}{l}\text { Kyoto Trial to } \\
\text { Evaluate the } \\
\text { Safety and } \\
\text { Efficacy of iPSC- } \\
\text { derived } \\
\text { dopaminergic } \\
\text { progenitors in } \\
\text { the treatment of } \\
\text { Parkinson's } \\
\text { Disease }\end{array}$ & $\begin{array}{l}\text { hiPSC-derived } \\
\text { dopaminergic } \\
\text { progenitors }\end{array}$ & & $\begin{array}{l}\text { Parkinson's } \\
\text { Disease }\end{array}$ & Japan & $\begin{array}{l}\text { Open } \\
\text { Label }\end{array}$ & 7 & Single arm & $\begin{array}{l}\text { Tran } \\
\text { into } \\
\text { stria }\end{array}$ \\
\hline $\begin{array}{l}\text { JPRN- } \\
\text { UMIN000026003 }\end{array}$ & $\begin{array}{l}\text { A Study of } \\
\text { transplantation } \\
\text { of allogenic } \\
\text { induced } \\
\text { pluripotent stem } \\
\text { cell (iPSC) } \\
\text { derived retinal } \\
\text { pigment } \\
\text { epithelium (RPE) } \\
\text { cell suspension } \\
\text { in subjects with } \\
\text { neovascular age } \\
\text { related macular } \\
\text { degeneration }\end{array}$ & $\begin{array}{l}\text { iPSC-derived } \\
\text { RPE }\end{array}$ & allogeneic & $\begin{array}{l}\text { Neovascular age } \\
\text { related macular } \\
\text { degeneration }\end{array}$ & Japan & $\begin{array}{l}\text { Open } \\
\text { Label }\end{array}$ & 5 & Single arm & $\begin{array}{l}\text { Sub } \\
\text { tran: }\end{array}$ \\
\hline
\end{tabular}




\begin{tabular}{|c|c|c|c|c|c|c|c|c|c|}
\hline ID number & Title & Cell type & Origin & Target disease & $\begin{array}{l}\text { Country or } \\
\text { area }\end{array}$ & $\begin{array}{l}\text { Study } \\
\text { design }\end{array}$ & $\begin{array}{l}\text { No. } \\
\text { patients } \\
\text { enrolled }\end{array}$ & Study groups & InteI \\
\hline $\begin{array}{l}\text { ChiCTR-OCB- } \\
15007054\end{array}$ & $\begin{array}{l}\text { Clinical study of } \\
\text { subretinal } \\
\text { transplantation } \\
\text { of clinical } \\
\text { human } \\
\text { embryonic stem } \\
\text { cells derived } \\
\text { retinal pigment } \\
\text { epitheliums in } \\
\text { treatment of dry } \\
\text { age-related } \\
\text { macular } \\
\text { degeneration } \\
\text { diseases }\end{array}$ & $\begin{array}{l}\text { hESC-derived } \\
\text { RPE }\end{array}$ & allogeneic & $\begin{array}{l}\text { Dry age-related } \\
\text { macular } \\
\text { degeneration }\end{array}$ & China & $\begin{array}{l}\text { Open } \\
\text { Label }\end{array}$ & 10 & Single arm & $\begin{array}{l}\text { Sub } \\
\text { tran: }\end{array}$ \\
\hline $\begin{array}{l}\text { ChiCTR-OCB- } \\
15005968\end{array}$ & $\begin{array}{l}\text { The clinical trial } \\
\text { of human } \\
\text { embryonic stem } \\
\text { cell derived } \\
\text { epithelial cells } \\
\text { transplantation } \\
\text { in the treatment } \\
\text { of severe ocular } \\
\text { surface } \\
\text { diseases }\end{array}$ & $\begin{array}{l}\text { hESC-derived } \\
\text { epithelial cells }\end{array}$ & allogeneic & $\begin{array}{l}\text { Severe Ocular } \\
\text { Surface Disease }\end{array}$ & China & & 20 & $\begin{array}{l}\text { Historical } \\
\text { control }\end{array}$ & $\begin{array}{l}\text { Corr } \\
\text { epith } \\
\text { cell } \\
\text { tran }\end{array}$ \\
\hline
\end{tabular}

Characteristics of all interventional studies. Abbreviations: $\mathrm{hESC}=$ human embryonic stem cells, hiPSC $=$ human induced pluripotent stem cell, RPE $=$ retinal $p$ human retinal pigment epithelium, MSC = mesenchymal stem cell, UK = United Kingdom.

\section{Discussion}

Human pluripotent stem cells hold great potential for novel therapeutic approaches to regenerate or replace functionally impaired tissues (21, 38-41). In addition, the use of autologous cells for in vitro disease modeling and drug testing without re-transplantation into the host has also become an increasingly important scientific branch of regenerative medicine $(42,43)$. Following the initial report by Yamanaka and Takahashi in 2006 (9), the number of scientific publications on pluripotent stem cells has virtually exploded over the past years. Consequently, it can be assumed that also the number of clinical trials, in the sense of studies on PSCs involving human subjects, may have been increasing in parallel. While scientific publications represent an indicator for the scientific interest in a certain technology, the number of clinical trials indicates how many attempts have been made to actually translate the technology from the bench to the clinical phase as it represents the final stage prior to a potential standard use in human patients. However, the published information contained in research studies is generally limited by a significant publication bias, implying that negative results may not be published at all due to rejection by editors or reviewers, competing interests or lack of interest to publish $(44,45)$. In addition, results may not be published due to a lack of interest by the sponsoring institution. Therefore, we have focused on the comprehensive analysis of the past and present status of clinical trials on pluripotent stem cells to generate an overview on the actual number and content of clinical trials involving this promising technology.

So far, several studies have been focusing on the trends in clinical trials involving "stem cells" in general. Monsarrat et al. published an analysis of clinical trials involving stem cells listed on "ClinicalTrials.gov". In this work he assessed the different organ systems and diseases involved in these trials, including comparisons between different study phases and stem cell types (32), T. Squillaro et al. focused on clinical trials involving "mesenchymal stem cells", investigating different clinical findings and therapeutic effects (34), Fung et al. analyzed to which extent authors of clinical trials involving stem cells had already published their results by using PubMed, Embase and Google Scholar (31). However, so far, there is no comprehensive, systematic analysis addressing the geographic distribution, concerned organ systems and used cell types of clinical trials on human pluripotent stem cells. In addition, these previous studies were either limited regarding the type of stem cell used, e.g. focusing on "multipotent stem cells" only,(34) and/or their search was only conducted in one database (mostly "ClinicalTrials.gov") (31-34). Even though "ClinicalTrials.gov" is the largest database for clinical trials and represented in more than 200 countries around the globe, a search query in this database does not guarantee completeness. Alternative meta-databases collecting data from even more countries and databases, such as the ICTRP database from the WHO, have not been included in several studies (46), which implies that some trials may have been missed.

Therefore, in the present analysis, we complemented our systematic search on "ClinicalTrials.gov" by using the ICTRP database of the WHO as well as by performing a search at each individual platform that is included in the ICTRP repository. This multi-step approach should enable the most complete overview on clinical trials involving "pluripotent stem cells". Following a stringent inclusion/exclusion procedure, 131 studies remained that could be classified as clinical trials involving PSCs. The magnitude of these studies (77.1\%) was of observational nature, which means that no cells were transplanted into patients for therapeutic use. These studies mainly included trials where cells were isolated from patients or volunteers for the subsequent use as part of reprogramming experiments. This also implies that only a minority of studies (22.9\%) were of an interventional study type, where cells were actually transplanted into patients for therapeutic purposes. From the view point of translational medicine, these interventional studies are of greater interest, since the introduction of the iPSC technology was associated with a significant hope for future clinical use in the sense of cellular transplantation (8, 47-50). While the total number of clinical trials involving iPSCs (74.8\%) was substantially higher than the ones involving ESCs (25.2\%), the picture changes completely when focusing on interventional studies. Here, in the majority (73.3\%) of trials ESCs were involved and only in few studies (26.7\%) iPSCs were used for the intervention. However, when considering the increasing number of trials on iPSCs, a future switch towards interventional iPSC trials might just be a matter of 
time. In particular the introduction of non-integrating transgene-free reprogramming approaches may further support the clinical translation of the iPSC technology as the issue of in situ carcinogenicity of iPSCs due to remaining viral particles may be solved by these technologies (51).

Also, when focusing on the geographical regions, where the studies have been performed, it becomes obvious that there are substantial differences between different study types. While regarding observational studies the greatest part of all trials was performed in the USA (41.6\%) and in France (16.8\%), the majority of interventional studies was performed in Asian countries (China $36.7 \%$, Japan 13.3\%, South Korea 10.0\%). The major reasons for this may be seen in the differences in legal and/or regulatory restrictions on embryonic stem cell research in Western countries, in different research policies as well as in different national ethical regulations of different countries concerning pluripotent stem cell research. $(7,52-55)$ In many countries of the European region, the harvest of stem cells from a human embryo for research purposes is prohibited, however, in some countries research can be conducted using imported pluripotent cells. (56) In the USA, stem cell research is regulated by National Academies (NAS) Guidelines, which allows the derivation of ESC lines from human embryos, however, additionally, some US states have adopted their own regulations (57). In China, where research on human embryos and cloning for therapeutic purposes is in general permitted, state regulations established in 2015 attempt to limit clinical trials using stem cells to research centres (58, 59). Other potential factors might be the differences in the focus of research institutions on a particular topic, the policies of funding agencies as well as the societal perceptions on pluripotent stem cell research in general (60).

When focusing on the targeted diseases of PSC clinical trials, it becomes evident that "sense organ diseases", more precisely ophthalmic diseases, are targeted in $24.4 \%$ (32) of all studies. Regarding the group of interventional studies even $63.3 \%$ of all trials addressed the eyes. The majority of observational studies was concerned with other non-communicable diseases $(25.7 \%, 26)$, cardiovascular diseases $(16.8 \%, 17)$, neurological disorders $(12.9 \%, 13)$ and ophthalmic diseases $(12.9 \%, 13)$. In particular the relatively high proportion of - especially interventional - clinical trials in the field of ophthalmology is striking. A major reason for this may not only lie in the different ocular pathologies that profit from cellular replacement, it may also be due to anatomic circumstances, since the eye is easily accessible for stem cell transplantation and in the case of adverse events life-threatening complications are scarce $(4,61)$. This lack of fatal complications represents a major advantage over diseases concerning other organ systems, such as cardiovascular diseases, when introducing a new therapeutic concept. However, also the pathophysiology of targeted ophthalmologic diseases forms the basis for the broader clinical investigation of hPSCs in this field. Ophthalmologic diseases, such as Stargardt's macular dystrophy or atrophic age-related macular degeneration, are predominantly treated as part of

these clinical trials $(5,18)$. These diseases share the pathophysiologic element of progressive cellular degeneration that may be treated by stem cells replacing the impaired tissues (5). In the end, it is the combination of all the reasons mentioned above that may form the basis for the disproportionally high fraction of PSC interventional clinical trials focusing on ophthalmologic diseases $(4,61)$.

Interestingly, an in-depth analysis of the group of interventional studies also revealed several limitations of these recent clinical trials on pluripotent stem cells. This includes a lack of placebo control groups ( $0 \%$ ) or untreated control groups (6.7\%), a lack of long-term follow-up periods (only one study with published results had a follow-up of $>12$ months) and a lack of reporting (only $27.8 \%$ of all interventional trials without active recruitment have already been published in a peer-reviewed journal). A major limitation of the present analysis, as well as of all studies focusing on the analysis of clinical trial databases in general, might be a reporting bias. In particular regarding observational studies, it has to be assumed that not all studies may have been registered on public databases, limiting the representativeness of the data on this type of trials.

\section{Conclusion}

This study shows that, although a large series of clinical trials involving PSCs has been registered in public databases, only a small part has been focusing on the actual transplantation of cells. The greatest part of these interventional studies was focusing on the use of ESCs in the field of ophthalmology and carried out in Asian countries. Therefore, in spite of the "hype" on iPSC research in recent years also fostered by the Nobel Prize in 2012 , the iPSC technology has not reached the clinical investigational phase on a broader scale yet. The future will tell us, if the iPSC technology will ultimately overcome the challenges associated with their clinical use - such as carcinogenicity, lack of in situ integration $(61,62)$, genomic instability (28), immunological rejection(29) or lack of quality control criteria (63) - and whether they will finally make its way into routine clinical use.

\section{Abbreviations}

PSC - Pluripotent stem cells

hiPSC - human induced pluripotent stem cell

hESC - human embryonic stem cell

ICTRP - International clinical trials registry platform

WHO - Word Health Organization

ANZCTR - Australian New Zealand Clinical Trials Registry

UK - United Kingdom

NPC - Neural precursor cell

BCVA - best corrected visual acuity

SCNT - somatic cell nuclear transfer 


\section{Declarations}

Ethics approval and consent to participate: Not applicable

Consent for publication: Not applicable

Competing interests: The authors have no conflict of interest to disclose.

Funding: Austrian Science Fund, Project number: P 30615

Authors' contributions: JD carried out the analysis of the data, helped to gather the original data and to draft the manuscript. DR helped to gather the original data and designed the figures. BW designed and coordinated the study and helped to draft the manuscript. All authors read and approved the final manuscript.

Acknowledgements: We would like to thank the following funding institutions for their support: Austrian Science Fund (FWF; P-30615), Medical Scientific Fund of the Mayer of the City of Vienna (MA-GMWF-501912-2019), Vienna Science and Technology Fund (WWTF; LS18-080), and institutional funding of the Medical University of Vienna, Austria.

Data availability statement: The data contained in this manuscript was derived from the following publicly available databases: "ClinicalTrials.gov" and the ICTRP database of the WHO (and its individual databases).

\section{References}

1. Abu-Dawud R, Graffmann N, Ferber S, Wruck W, Adjaye J. Pluripotent stem cells: induction and self-renewal. Philosophical transactions of the Royal Society of London Series B, Biological sciences. 2018;373(1750).

2. Kimbrel EA, Lanza R. Pluripotent stem cells: the last 10 years. Regen Med. 2016;11(8):831-47.

3. Mahla RS. Stem Cells Applications in Regenerative Medicine and Disease Therapeutics. International journal of cell biology. 2016;2016:24.

4. da Cruz L, Fynes K, Georgiadis O, Kerby J, Luo YH, Ahmado A, et al. Phase 1 clinical study of an embryonic stem cell-derived retinal pigment epithelium patch in age-related macular degeneration. Nature biotechnology. 2018;36(4):328-37.

5. Schwartz SD, Regillo CD, Lam BL, Eliott D, Rosenfeld PJ, Gregori NZ, et al. Human embryonic stem cell-derived retinal pigment epithelium in patients with age-related macular degeneration and Stargardt's macular dystrophy: follow-up of two open-label phase 1/2 studies. Lancet (London, England).

2015;385(9967):509-16.

6. Shroff G. Human Embryonic Stem Cell Therapy in Chronic Spinal Cord Injury: A Retrospective Study. Clin TransI Sci. 2016;9(3):168-75.

7. de Wert G, Mummery C. Human embryonic stem cells: research, ethics and policy. Human reproduction (Oxford, England). 2003;18(4):672-82.

8. Robinton DA, Daley GQ. The promise of induced pluripotent stem cells in research and therapy. Nature. 2012;481(7381):295-305.

9. Takahashi K, Yamanaka S. Induction of Pluripotent Stem Cells from Mouse Embryonic and Adult Fibroblast Cultures by Defined Factors. Cell. 2006;126(4):663-76.

10. Hofrichter M, Nimtz L, Tigges J, Kabiri Y, Schröter F, Royer-Pokora B, et al. Comparative performance analysis of human iPSC-derived and primary neural progenitor cells (NPC) grown as neurospheres in vitro. Stem cell research. 2017;25:72-82.

11. Generali M, Casanova EA, KehI D, Wanner D, Hoerstrup SP, Cinelli P, et al. Autologous endothelialized small-caliber vascular grafts engineered from bloodderived induced pluripotent stem cells. Acta biomaterialia. 2019;97:333-43.

12. Sundberg M, Bogetofte H, Lawson T, Jansson J, Smith G, Astradsson A, et al. Improved cell therapy protocols for Parkinson's disease based on differentiation efficiency and safety of hESC-, hiPSC-, and non-human primate iPSC-derived dopaminergic neurons. Stem cells (Dayton, Ohio). 2013;31(8):1548-62.

13. Takahashi J. Strategies for bringing stem cell-derived dopamine neurons to the clinic: The Kyoto trial. Progress in brain research. 2017;230:213-26.

14. Pagliuca FW, Millman JR, Gürtler M, Segel M, Van Dervort A, Ryu JH, et al. Generation of functional human pancreatic $\beta$ cells in vitro. Cell. 2014;159(2):428-39.

15. Wang Y, Hu J, Jiao J, Liu Z, Zhou Z, Zhao C, et al. Engineering vascular tissue with functional smooth muscle cells derived from human iPS cells and nanofibrous scaffolds. Biomaterials. 2014;35(32):8960-9.

16. Wimmer RA, Leopoldi A, Aichinger M, Wick N, Hantusch B, Novatchkova M, et al. Human blood vessel organoids as a model of diabetic vasculopathy. Nature. 2019;565(7740):505-10.

17. Mehat MS, Sundaram V, Ripamonti C, Robson AG, Smith AJ, Borooah S, et al. Transplantation of Human Embryonic Stem Cell-Derived Retinal Pigment Epithelial Cells in Macular Degeneration. Ophthalmology. 2018;125(11):1765-75.

18. Mandai M, Watanabe A, Kurimoto Y, Hirami Y, Morinaga C, Daimon T, et al. Autologous Induced Stem-Cell-Derived Retinal Cells for Macular Degeneration. The New England journal of medicine. 2017;376(11):1038-46.

19. Stoddard-Bennett T, Reijo Pera R. Treatment of Parkinson's Disease through Personalized Medicine and Induced Pluripotent Stem Cells. Cells. 2019;8(1).

20. Menasché P, Vanneaux V, Hagège A, Bel A, Cholley B, Parouchev A, et al. Transplantation of Human Embryonic Stem Cell-Derived Cardiovascular Progenitors for Severe Ischemic Left Ventricular Dysfunction. Journal of the American College of Cardiology. 2018;71(4):429-38. 
21. Braganca J, Lopes JA, Mendes-Silva L, Almeida Santos JM. Induced pluripotent stem cells, a giant leap for mankind therapeutic applications. World journal of stem cells. 2019;11(7):421-30.

22. Zhu H, Lensch MW, Cahan P, Daley GQ. Investigating monogenic and complex diseases with pluripotent stem cells. Nature reviews Genetics. 2011;12(4):266-75.

23. Fu X, Xu Y. Challenges to the clinical application of pluripotent stem cells: towards genomic and functional stability. Genome Medicine. $2012 ; 4(6): 55$.

24. Quinlan AR, Boland MJ, Leibowitz ML, Shumilina S, Pehrson SM, Baldwin KK, et al. Genome sequencing of mouse induced pluripotent stem cells reveals retroelement stability and infrequent DNA rearrangement during reprogramming. Cell stem cell. 2011;9(4):366-73.

25. Laurent LC, Ulitsky I, Slavin I, Tran H, Schork A, Morey R, et al. Dynamic changes in the copy number of pluripotency and cell proliferation genes in human ESCs and iPSCs during reprogramming and time in culture. Cell stem cell. 2011;8(1):106-18.

26. Ben-David U, Benvenisty N. The tumorigenicity of human embryonic and induced pluripotent stem cells. Nature reviews Cancer. 2011;11(4):268-77.

27. Zhao T, Zhang Z-N, Rong Z, Xu Y. Immunogenicity of induced pluripotent stem cells. Nature. 2011;474(7350):212-5.

28. Yoshihara M, Oguchi A, Murakawa Y. Genomic Instability of iPSCs and Challenges in Their Clinical Applications. Advances in experimental medicine and biology. 2019;1201:23-47.

29. Liu X, Li W, Fu X, Xu Y. The Immunogenicity and Immune Tolerance of Pluripotent Stem Cell Derivatives. Frontiers in immunology. $2017 ; 8: 645$.

30. Fujikawa T, Oh SH, Pi L, Hatch HM, Shupe T, Petersen BE. Teratoma formation leads to failure of treatment for type I diabetes using embryonic stem cellderived insulin-producing cells. The American journal of pathology. 2005;166(6):1781-91.

31. Fung M, Yuan Y, Atkins H, Shi Q, Bubela T. Responsible Translation of Stem Cell Research: An Assessment of Clinical Trial Registration and Publications. Stem Cell Reports. 2017;8(5):1190-201.

32. Monsarrat P, Vergnes JN, Planat-Benard V, Ravaud P, Kemoun P, Sensebe L, et al. An Innovative, Comprehensive Mapping and Multiscale Analysis of Registered Trials for Stem Cell-Based Regenerative Medicine. Stem Cells Transl Med. 2016;5(6):826-35.

33. Negoro T, Takagaki Y, Okura H, Matsuyama A. Trends in clinical trials for articular cartilage repair by cell therapy. NPJ Regen Med. $2018 ; 3: 17$.

34. Squillaro T, Peluso G, Galderisi U. Clinical Trials With Mesenchymal Stem Cells: An Update. Cell Transplant. 2016;25(5):829-48.

35. ClinicalTrials.gov https://clinicaltrials.gov/ [

36. International Clinical Trials Registry Platform (ICTRP) https://www.who.int/ictrp/en/ [

37. James SL, Abate D, Abate KH, Abay SM, Abbafati C, Abbasi N, et al. Global, regional, and national incidence, prevalence, and years lived with disability for 354 diseases and injuries for 195 countries and territories, 1990\&\#x2013;2017: a systematic analysis for the Global Burden of Disease Study 2017. The Lancet. 2018;392(10159):1789-858.

38. Cyranoski D. 'Reprogrammed' stem cells approved to mend human hearts for the first time. Nature. 2018;557(7707):619-20.

39. Stoddard-Bennett T, Reijo Pera R. Treatment of Parkinson's Disease through Personalized Medicine and Induced Pluripotent Stem Cells. Cells. 2019;8(1):26.

40. Wu J, Izpisua Belmonte JC. Dynamic Pluripotent Stem Cell States and Their Applications. Cell Stem Cell. 2015;17(5):509-25.

41. Trounson A, DeWitt ND. Pluripotent stem cells progressing to the clinic. Nature Reviews Molecular Cell Biology. 2016;17(3):194-200.

42. Avior Y, Sagi I, Benvenisty N. Pluripotent stem cells in disease modelling and drug discovery. Nature Reviews Molecular Cell Biology. 2016;17(3):170-82.

43. Rowe RG, Daley GQ. Induced pluripotent stem cells in disease modelling and drug discovery. Nature Reviews Genetics. 2019;20(7):377-88.

44. Mlinarić A, Horvat M, Šupak Smolčić V. Dealing with the positive publication bias: Why you should really publish your negative results. Biochemia medica. 2017;27(3):030201.

45. Nair AS. Publication bias - Importance of studies with negative results! Indian journal of anaesthesia. 2019;63(6):505-7.

46. Negoro T, Okura H, Maehata M, Hayashi S, Yoshida S, Takada N, et al. Trends in clinical trials for stroke by cell therapy: data mining ClinicalTrials.gov and the ICTRP portal site. npj Regenerative Medicine. 2019;4.

47. Nordin N, Lai MI, Veerakumarasivam A, Ramasamy R, Abdullah S, Wendy-Yeo WY, et al. Induced pluripotent stem cells: history, properties and potential applications. Med J Malaysia. 2011;66(1):4-9.

48. Omole AE, Fakoya AOJ. Ten years of progress and promise of induced pluripotent stem cells: historical origins, characteristics, mechanisms, limitations, and potential applications. PeerJ. 2018;6:e4370.

49. Liu J. Induced pluripotent stem cell-derived neural stem cells: new hope for stroke? Stem Cell Research \& Therapy. 2013;4(5):115.

50. Lu X, Zhao T. Clinical Therapy Using iPSCs: Hopes and Challenges. Genomics, Proteomics \& Bioinformatics. 2013;11(5):294-8.

51. Slamecka J, Salimova L, McClellan S, van Kelle M, Kehl D, Laurini J, et al. Non-integrating episomal plasmid-based reprogramming of human amniotic fluid stem cells into induced pluripotent stem cells in chemically defined conditions. Cell cycle (Georgetown, Tex). 2016;15(2):234-49.

52. Al-Sayyari RA. Ethical aspects of stem cells research. Saudi journal of kidney diseases and transplantation : an official publication of the Saudi Center for Organ Transplantation, Saudi Arabia. 2005;16(4):606-11.

53. Volarevic V, Markovic BS, Gazdic M, Volarevic A, Jovicic N, Arsenijevic N, et al. Ethical and Safety Issues of Stem Cell-Based Therapy. International journal of medical sciences. 2018;15(1):36-45.

54. Neaves W. The status of the human embryo in various religions. Development (Cambridge, England). 2017;144(14):2541-3.

55. Lo B, Parham L. Ethical issues in stem cell research. Endocrine reviews. 2009;30(3):204-13.

56. Regulation of stem cell research in Europe https://www.eurostemcell.org [

Page 12/17 
57. Hynes RO. US policies on human embryonic stem cells. Nature Reviews Molecular Cell Biology. 2008;9(12):993-7.

58. Liao L, Li L, Zhao RC. Stem cell research in China. Philosophical transactions of the Royal Society of London Series B, Biological sciences. 2007;362(1482):1107-12.

59. Rosemann A, Sleeboom-Faulkner M. New regulation for clinical stem cell research in China: expected impact and challenges for implementation. Regenerative medicine. 2016;11(1):5-9.

60. Dajani R. Jordan's stem-cell law can guide the Middle East. Nature. 2014;510(7504):189-.

61. Takahashi M. [Retinal Cell Therapy Using iPS Cells]. Nippon Ganka Gakkai zasshi. 2016;120(3):210-24; discussion 25.

62. Liu J. Induced pluripotent stem cell-derived neural stem cells: new hope for stroke? Stem cell research \& therapy. 2013;4(5):115.

63. Doss MX, Sachinidis A. Current Challenges of iPSC-Based Disease Modeling and Therapeutic Implications. Cells. 2019;8(5).

64. Schwartz SD, Hubschman JP, Heilwell G, Franco-Cardenas V, Pan CK, Ostrick RM, et al. Embryonic stem cell trials for macular degeneration: a preliminary report. Lancet (London, England). 2012;379(9817):713-20.

\section{Figures}

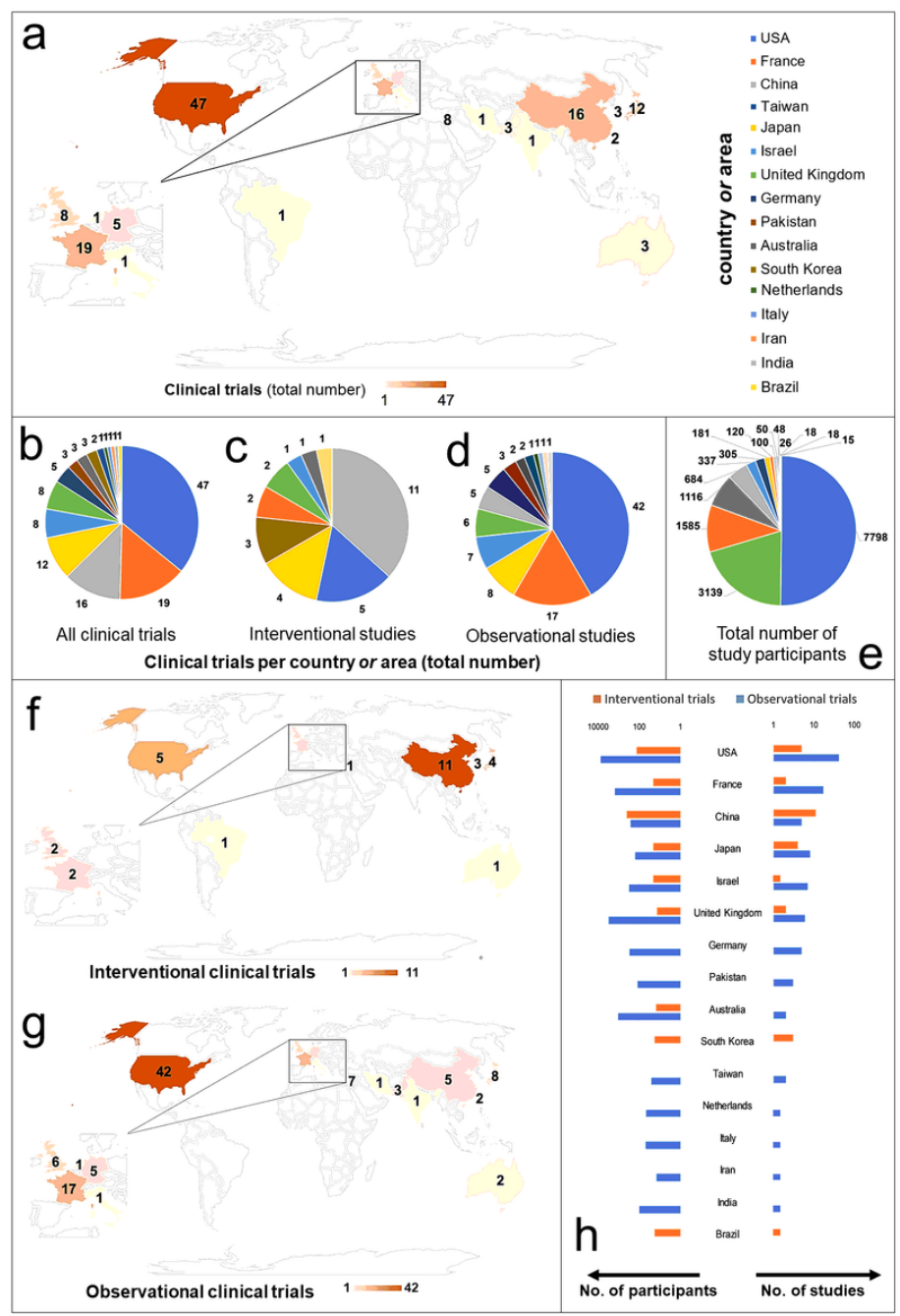

Figure 1

Geographic distribution of studies involving human pluripotent stem cells. a) Global distribution of all clinical trials involving human pluripotent stem cells, b) Distribution of all clinical trials involving human pluripotent stem cells, c) Global distribution of observational clinical trials involving pluripotent stem cells, d) Distribution of interventional clinical trials involving pluripotent stem cells, e) Global distribution of all study participants, f) Global distribution of interventional clinical trials involving pluripotent stem cells, g) Global distribution of observational clinical trials involving pluripotent stem cells, h) Comparison between interventional and observational clinical trials and study participants. The horizontal axes have logarithmic scales of different sizes. 


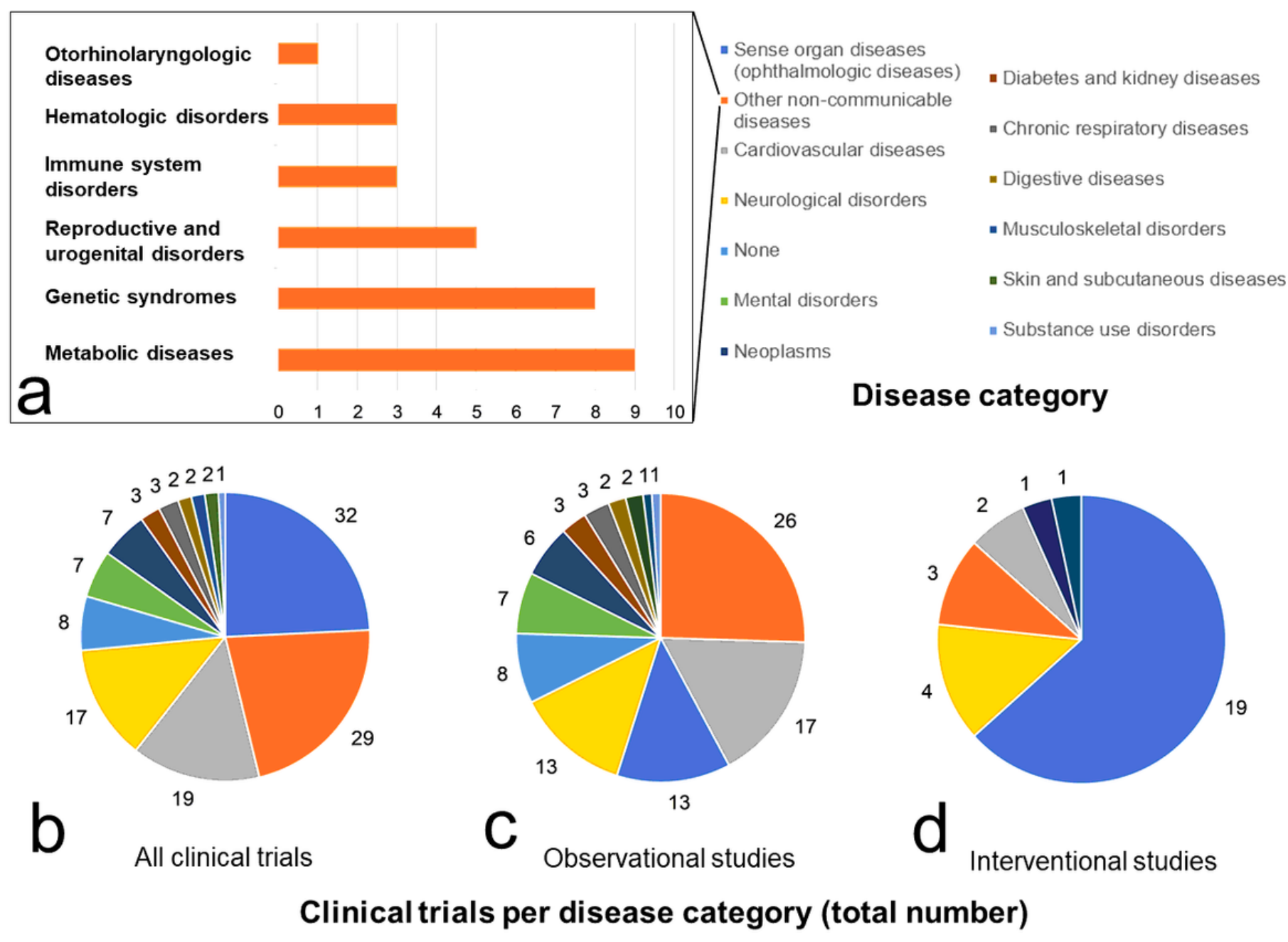

Figure 2

Disease categories targeted in clinical trials involving human pluripotent stem cells. The legend shown on the top right of Figure 2 is color coordinated with all three pie charts. a) Sub-classification of the category "non-communicable diseases" b) Distribution of clinical trials involving pluripotent stem cells dependent on the targeted disease c) Distribution of observational clinical trials dependent on the targeted disease, d) Distribution of interventional clinical trials dependent on the targeted disease. 


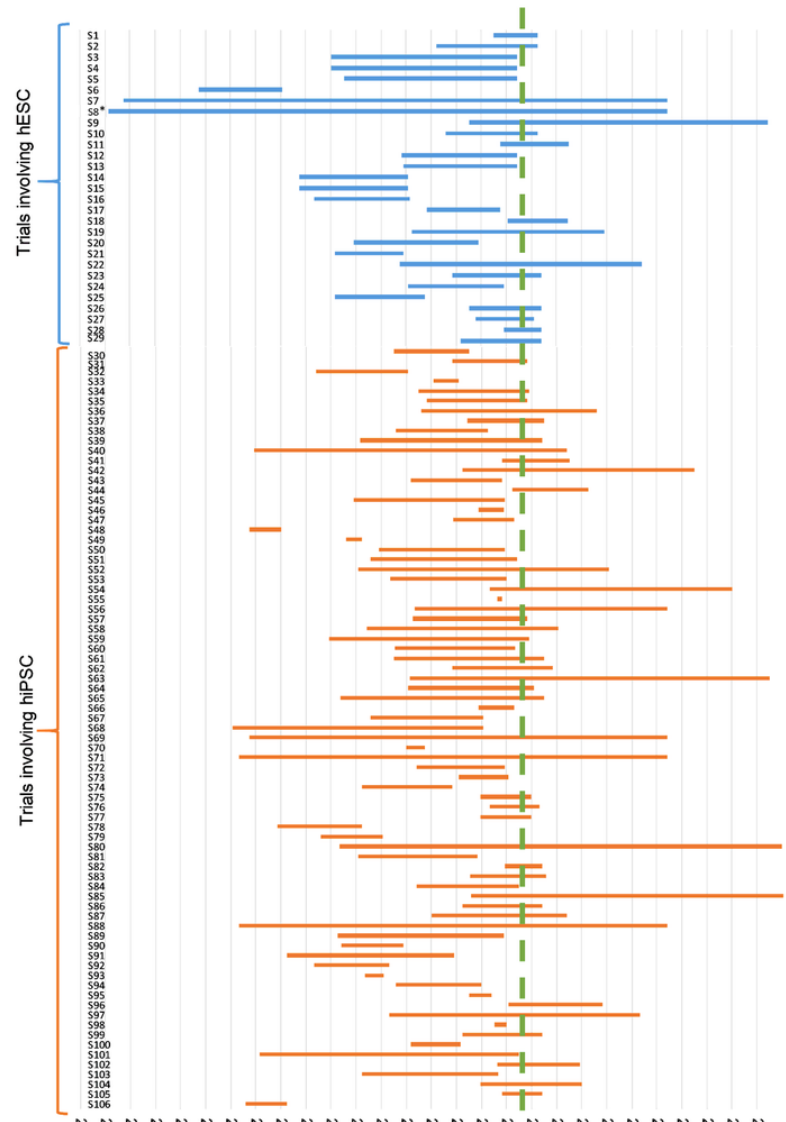

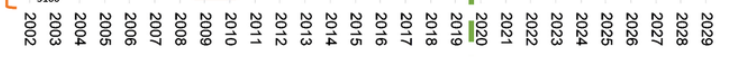

\section{Figure 3}

Comparison of starting point and study duration dependent on the use of either one of the two stem cell types, hiPSC and hESC. The blue bars show the starting point and study duration of clinical studies involving hESCs, the orange bars depict the same information for studies involving hiPSC. The green dashed line shows the time of data collection. The $x$ axis shows the time in years, the $y$ axis shows the study numbers. A list of the respective studies can be found in Suppl. Table 01. 


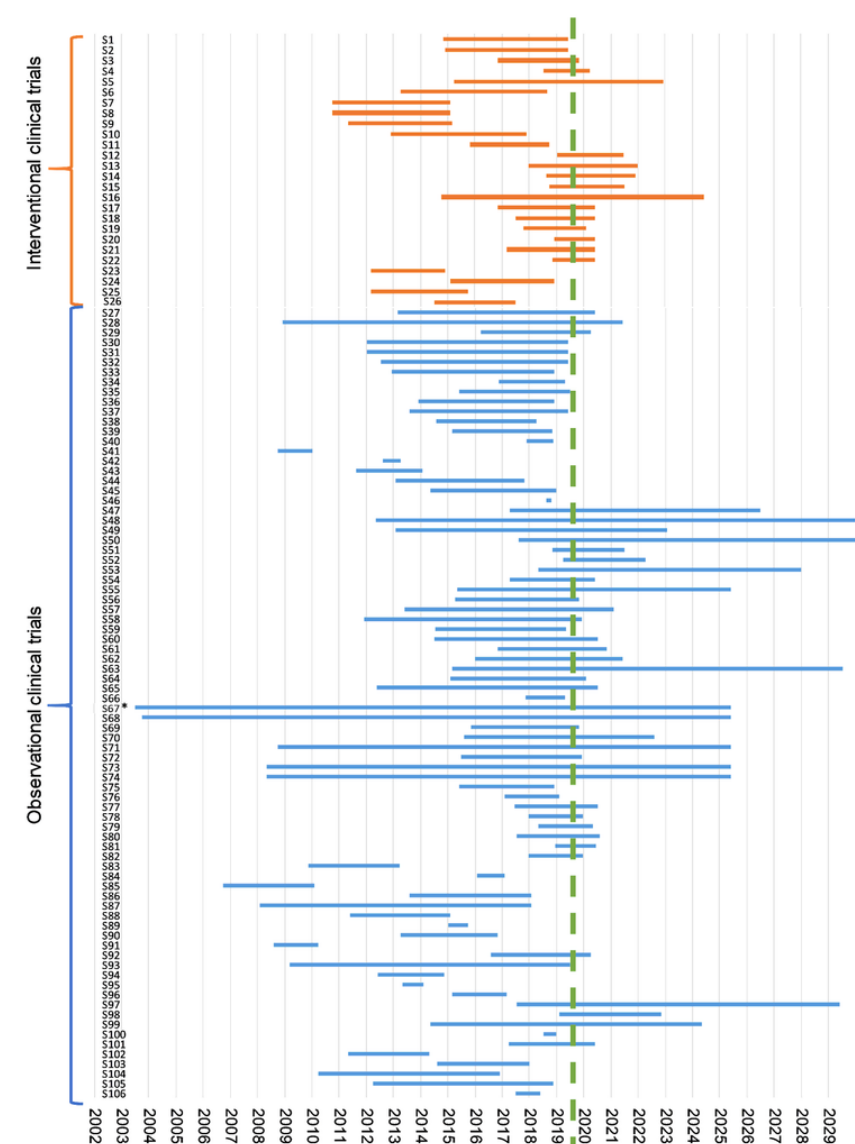

\section{Figure 4}

Comparison of starting point and (scheduled) study duration dependent on the study design. The blue bars show the starting point and study duration of interventional clinical studies, the orange bars depict the same information for observational clinical trials. The green dashed line shows the time of data collection. The $x$ axis shows the time in years, the $y$ axis shows the study numbers. A list of the respective studies can be found in Suppl. Table 01 . 

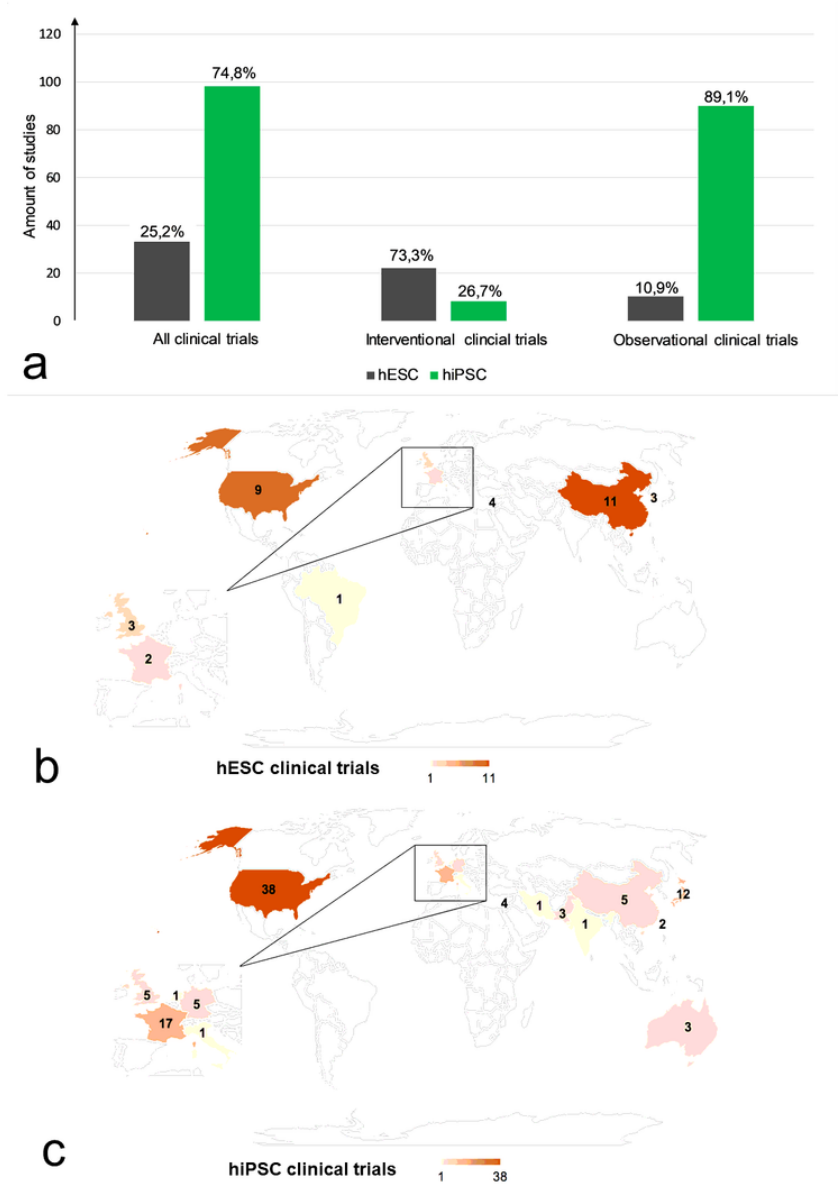

\section{Figure 5}

Usage of pluripotent stem cell types (hESC and iPSC) dependent on geographic distribution and study design. a) Distribution of all clinical trials and interventional and observational trials respectively, dependent on the usage of hESC or hiPSC, b) Choropleth map presenting the geographic distribution of all clinical trials involving hESCs, c) Choropleth map presenting the geographic distribution of all clinical trials involving hiPSCs.

\section{Supplementary Files}

This is a list of supplementary files associated with this preprint. Click to download.

- SupplementaryTable1.docx

- SupplementaryTable2.docx

- SupplementaryFigure12.tif

- SupplementaryFigure22.tif

- SupplemenatryFigure3.tif

- SupplementaryFigure4.tif 